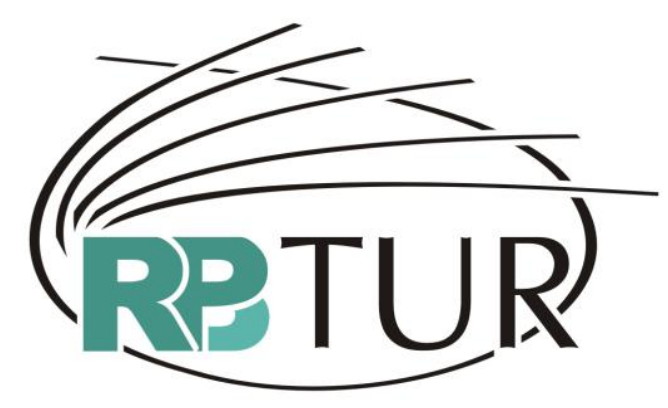

REVISTA BRASILEIRA DE PESQUISA EM TURISMO

\title{
APROFUNDANDO O OLHAR DO TURISTA: CONSIDERAÇÕES ACERCA DE SUAS DETERMINANTES SOCIAIS
}

\author{
GOING DEEPER ON THE TOURIST GAZE: CONSIDERATIONS \\ ABOUT ITS SOCIAL DETERMINANTS
}

\section{PROFUNDIZANDO LA MIRADA DEL TURISTA: CONSIDERACIONES SOBRE LOS DETERMINANTES SOCIALES DEL MISMO}

Erik Silva Omena de Melo

\begin{abstract}
Resumo: Este artigo visa caminhar na direção de uma maior compreensão dos processos sociais que motivam turistas a adotar diferentes comportamentos nos locais visitados, utilizando como chave de leitura as relações interclasses no contexto da sociedade ocidental moderna. Neste sentido, a reflexão sugerida tem por base contribuições teóricas de importantes autores, como John Urry, Pièrre Bourdieu e Jost Krippendorf, buscando desenvolvê-las de forma a subsidiar novas abordagens do turismo que estejam preocupadas com um maior desenvolvimento do saber processual acerca da atividade, de maneira a se contrapor às tendências que privilegiam o dito saber proposicional. Verificou-se que a construção do olhar do turista tem complexas relações dialéticas entre algumas principais determinantes, as quais estão mergulhadas no contexto das diferentes posições ocupadas pelos sujeitos do fenômeno turístico no campo social, e que têm se consolidado através de um longo processo que vem se manifestando desde o século XVII, atingindo sua forma atual em meados do século $X X$.
\end{abstract}

Palavras-chave: O olhar do turista. Processos sociais. Classes sociais.

Abstract: This article aims to a better understanding of social processes which lead tourists to different kinds of behavior at the places they visit, having as a frame the way social classes are related in western modern society. Theoretical contribution from important scientists as John Urry, Piérre Bourdieu and Jost Krippendorf are developed in search of new approaches to enhence processual knowledge in tourism

\footnotetext{
${ }^{1}$ Turismólogo, mestrando em Planejamento Urbano e Regional - UFRJ/IPPUR. Email: erickomena@gmail.com
} 
MELO, Erik Silva Omena de. Aprofundando o olhar do turista: considerações acerca de suas determinantes sociais. Revista Brasileira de Pesquisa em Turismo. v. 3, n. 2, p. 71-94, ago 2009.

ISSN: $1982-6125$

instead of proposicional. It was found that tourist gaze is a construction crossed by dialectic and complex relations among some determinant factors, embedded in the different kind of roles played by subjects in the social arena, which have been consolidated during a long process beginning in XVII century and taking its present feature in the middle of the XXth.

Keywords: Tourist gaze. Social processes. Social classes.

Resumen: Este artículo tiene como objetivo una mejor comprensión de los procesos sociales que motivan los turistas a adoptar diferentes comportamientos en los lugares que visitan, utilizando como clave de lectura las relaciones entre clases en el contexto de la sociedad occidental moderna. La reflexión tiene como base contribuciones teóricas de autores como John Urry, Pièrre Bourdieu y Jost Krippendorf las cuales contribuyen con nuevas aproximaciones al turismo preocupadas con el desarrollo del saber procesual, como contrapunto a las tendencias que priorizan el llamado saber proposicional. Se verificó que la construcción de la mirada del turista tiene complejas relaciones dialécticas entre algunas principales determinantes, que están inmersas en el contexto de las diferentes posiciones ocupadas por los sujetos del fenómeno turístico en el campo sicial y que se han consolidado a través de un largo proceso que se viene manifestando desde el siglo XVII, tomando su forma actual a mediados del siglo XX.

Palabras clave: Mirada del turista. Procesos sociales. Clases sociales.

\section{INTRODUÇÃO}

Os estudos relacionados ao turismo têm se pautado por uma ampla variedade de abordagens realizadas através das mais diversas disciplinas, como a economia, a sociologia, a psicologia, a antropologia, a geografia, o planejamento urbano, a administração, dentre outras. Isto se deve ao alto grau de complexidade do fenômeno turístico e de suas múltiplas facetas. Dentro deste universo, verifica-se que grande parte do conhecimento produzido se caracteriza por uma aproximação mais pragmática, que busca desenvolver processos e formas de agir e intervir na realidade, podendo ser chamado de "saber proposicional" e, muitas vezes, patrocinado por agentes e instituições interessados no seu desenvolvimento, enquanto aqueles estudos que têm por objetivo aprofundar a compreensão do fenômeno turístico em si, relacionados ao "saber processual" (TRIBE, 1997), apresentam avanços bem mais tímidos. 
Neste sentido, este artigo procura se contrapor à tendência que privilegia o saber proposicional em detrimento do processual, de forma a contribuir para a evolução da compreensão do fenômeno turístico, especialmente no que se refere à construção de uma abordagem que considere a multidisciplinaridade necessária para se abarcar toda a sua complexidade, ressaltando-se a busca pelo entendimento e identificação de suas principais determinantes sociais. Para tanto, utilizar-se-ão trabalhos de alguns autores que já vêm caminhando nesta direção, principalmente os do sociólogo John Urry (2001), configurandose estes como ponto de partida para uma nova abordagem das motivações do turista e de suas condicionantes.

As variadas tentativas de conceituação e teorização do turismo, as quais vêm sendo engendradas desde o início do século $X X$ até os dias atuais, são marcadas em sua maioria, senão em sua totalidade, pelo reconhecimento de três componentes essenciais ao fenômeno. A primeira delas é o turista, ou seja, aquele que pratica o turismo e é fundamental para sua existência. A segunda consiste na motivação da primeira, ou seja, as razões que fazem com que indivíduos saiam de seus ambientes de vivência e se desloquem para outros, uma vez que, de acordo com suas motivações (de se exercer ou não uma atividade remunerada, por exemplo), este deslocamento pode não ser caracterizado como turismo. E a terceira é representada pelo retorno ao local de origem (FERNÁNDEZ FUSTER, 1971).

Ressalte-se, entretanto, que as motivações assumem posição destacada, pois sem elas o turista não se constitui, isto é, não ocorre o deslocamento que o caracteriza e muito menos a sua volta ao cotidiano. Além disso, sua compreensão (destas motivações) poderia apontar para caminhos de melhor apreensão dos impactos sócio-espaciais e econômicos no destino visitado, já que é esta motivação que irá conduzir o comportamento destes agentes durante a prática turística, assim como daqueles que referenciam suas condutas nestes comportamentos e expectativas, dentre os quais se encontram os diversos prestadores de serviços envolvidos no turismo e as 
populações receptoras (CRUZ, 2002). No entanto, é importante ter em mente que "os fatores de motivação, que propiciam esse movimento pelo mundo, são inúmeros. Alguns são facilmente detectados; outros, por envolver muita subjetividade, são difíceis de ser avaliados" (CASTROGIOVANNI, 2004 apud PANOSSO NETTO, 2005, p. 29). Quanto mais próxima do nível individual estiver esta subjetividade, mais difícil será a tentativa de apreendê-la. Para que a compreensão da realidade seja viável, a chave de leitura utilizada não poderá, portanto, ser o indivíduo, mas sim, grupos sociais, pois a percepção da heterogeneidade destes grupos e de suas motivações e comportamentos apresentam maior acessibilidade.

\section{O olhar do turista}

Para tanto, Urry (2001) destaca-se como importante autor, criando como categoria-chave de análise da atividade o "olhar do turista". Examinando-se os apontamentos realizados por este autor a respeito do olhar do turista, o qual seria a subjetividade que intermedia a relação entre os diferentes turistas e os lugares visitados, pode-se enumerar quatro aspectos centrais na sua constituição, quais sejam: a expectativa de ruptura com o cotidiano, a forma de se vivenciar a experiência turística (em função da classe e grupo considerado e de seus respectivos habitus), a busca por status e a manipulação do olhar do turista, conforme demonstra a ilustração 1 . 


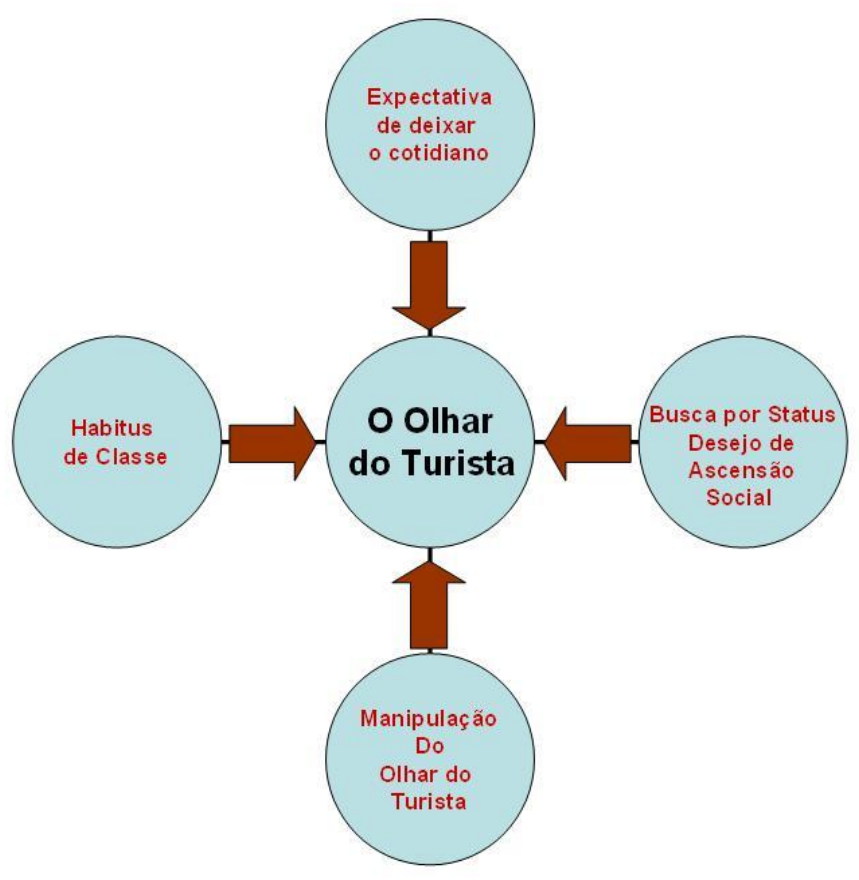

Ilustração 1 - A constituição do olhar do turista

Fonte: Urry (2001)

No entanto, algumas ressalvas devem ser feitas em relação a esta esquematização, que tem por objetivo facilitar o entendimento da realidade analisada. A primeira delas é a de que estes não são os únicos elementos que determinam o olhar do turista, mas sim os principais, especialmente no que concerne à sociedade moderna ocidental. A segunda é a de que os mesmos não são independentes, mas, ao contrário, se inter-relacionam, muitas vezes contraditoriamente, sempre se influenciando e se interpenetrando. Por último, é importante considerar que estes elementos estão sujeitos às determinações do contexto histórico em que estão inseridos.

A compreensão da contribuição de cada um destes fatores na constituição do olhar e o aprofundamento da reflexão na direção de suas peculiaridades são importantes para se entender como estão inseridos na estrutura que abrange não só o olhar do turista, mas ainda os espaços de 
ISSN: $1982-6125$

consumo turístico e o planejamento e promoção territorial, que deverá ser melhor explicitada em um outro momento.

\section{A ruptura com o cotidiano}

Pode-se dizer que a ruptura com o cotidiano é característica essencial do turismo. Apesar de não existir um único olhar do turista enquanto tal, apesar deste variar de acordo com grupos sociais, período histórico e sociedade analisados, e apesar de não haver uma experiência universal para todos os turistas,

[...] o olhar do turista, em qualquer período histórico, é construído em relacionamento com o seu oposto, com formas não-turísticas de experiência e de consciência social: o que faz com que um determinado olhar do turista dependa daquilo com que ele contrasta; quais são as formas de experiência nãoturística (URRY, 2001, p.16).

Através da constatação do fato de que estas experiências não-turísticas são, sobretudo, as baseadas no lar e no trabalho remunerado, pode-se concluir que, tendo-se em vista as diferenças existentes no cotidiano, no lar e no trabalho dos diversos grupos sociais, as experiências turísticas também serão diversas. Entretanto, esta motivação de ordem mais elementar para a prática do turismo, isto é, a ruptura com o cotidiano, deve ser aplicada para os diferentes grupos sociais, por ser comum às suas práticas. Assim, é a divisão binária entre cotidiano/ordinário e anticotidiano/extraordinário que caracteriza essencialmente as distintas motivações. Ainda que muitos turistas recorram a alguns artifícios para não se sentirem muito deslocados, os objetos potenciais do olhar do turista precisam ser diferentes de algum modo de sua vida cotidiana. Esta ruptura com o cotidiano na sociedade moderna é largamente influenciada pelo ambiente urbano cada vez mais hostil, principalmente nas grandes cidades, o que impele os habitantes dos grandes centros à 
necessidade de evasão (KRIPENDORF, 1989). Para Kripendorf, esta evasão se situa dentro de um contexto mais amplo, representado pelo dito ciclo da reconstituição, no qual a vida é compartimentalizada em diferentes esferas cada vez mais separadas: a da moradia, a do trabalho e a do lazer, sendo que as viagens "evasivas" se encontram nesta última. Neste sentido, estas três esferas estão no pólo do cotidiano, porém parte da esfera do lazer possui uma abertura para o pólo oposto, isto é, o do extracotidiano. O mal-estar proveniente dos problemas urbanos e também da alienação e da exaustão do trabalho teria as viagens de lazer como contraponto, caracterizando um mecanismo de regeneração da saúde desta população perturbada por estes efeitos colaterais do crescimento econômico e da urbanização. O ciclo de reconstituição recebe esse nome, pois a viagem a lazer nada mais seria do que um momento de reencontro com a liberdade perdida no cotidiano e de afastamento da coercitiva realidade, a fim de proporcionar um novo ânimo para posteriormente retomá-la com as "energias recarregadas". No entanto, muitas vezes o comportamento verificado nestas viagens por parte de alguns grupos sociais acaba por se assemelhar àqueles relacionados à alienação, às imposições e às coerções existentes no próprio local de origem, o que pode, ao invés de aliviar a tensão, reforçá-la ainda mais. Este quadro de descontentamento é agravado na atual sociedade de consumo "pós-moderna" onde a precarização e inconstância das relações sociais aliadas à exacerbação do estímulo à mobilidade e ao consumo - que nem sempre pode ser acompanhada por respostas à altura dos consumidores - resultam num ambiente de inquietação e insatisfação jamais visto (BAUMAN, 1999).

Como poderá ser observado, a idéia da reconstituição está presente no discurso legitimador e incentivador destas viagens, propagado por sujeitos e instituições envolvidos na publicidade dos destinos turísticos e que procuram direcionar a construção do olhar do turista e suas expectativas de consumo. Todavia, este não é o único artifício utilizado e nem é o único elemento existente nas motivações que impulsionam à ruptura com o cotidiano, 
demonstrando-se apenas como um dentre vários. Esta evasão pode ocorrer em função de outras razões que não somente a fuga das coerções sofridas no ambiente urbano e no mundo do trabalho, como a necessidade de novas experiências que não poderiam ser vividas no local habitado em função de clima e aspectos culturais diferentes, por exemplo. Contudo, o importante aqui não é tanto compreender o âmbito das razões mais generalizadas de busca por esta ruptura, mas o das motivações mais particularizadas dos grupos sociais.

\section{Como vivenciar a experiência turística}

O olhar do turista se divide em olhar romântico e olhar coletivo. O olhar romântico prioriza a observação de paisagens, de preferência aquelas que possuam importância simbólica, sem a presença de grandes grupos. Na forma romântica do olhar do turista, a ênfase está na beleza natural intocada, na "solidão, na privacidade e em um relacionamento pessoal e semi-espiritual com o objeto do olhar" (URRY, 2001, p.69).

Em contraposição ao olhar romântico está o olhar coletivo, identificado como aquele que pressupõe apreciar determinado lugar na presença de outras pessoas que sejam, geralmente, do mesmo grupo social. O olhar coletivo necessita da presença de um grande número de pessoas, que "dão uma atmosfera ou um sentido carnavalesco a um lugar. Indicam que aquele é o lugar onde se deve estar e que não se deve ir para outras paragens" (URRY, 2001, p.70).

De uma maneira geral, o olhar romântico tem sido relacionado à aristocracia e às classes mais altas, enquanto que o olhar coletivo às classes populares (URRY, 2001; NERY, 1998). Esta relação entre preferências, comportamentos, formas de olhar e as classes sociais deve ser compreendida com o auxílio do conceito de habitus, elaborado por Bourdieu (2007), o qual sugere que cada classe social possui um sistema de classificação que opera abaixo do nível da consciência individual e que se inscreve nas práticas que 
orientam as pessoas, nas disposições corporais, nos gostos e aversões. Na verdade, este sistema, presente no nível inconsciente do grupo social, é produto das condições materiais e de sua posição dentro do campo social às quais está submetido. Desse modo, as diferentes classes, assim como as próprias frações de classe, se diferenciam em seus comportamentos, em suas práticas e em seus gostos e aversões, os quais são condicionados pelos seus diferentes habitus. Claro está que a posição destes grupos e suas condições de existência dentro do espaço social são caracterizadas por suas respectivas posses de capital econômico e cultural, tanto no que se refere ao seu volume quanto à sua estrutura, ou seja, sua distribuição entre estes dois tipos.

Assim, as classes dominantes apresentam maior quantidade de capital econômico e cultural do que as classes dominadas, o que gera habitus diferentes em relação a estas posições ocupadas em decorrência desta maior ou menor posse de capitais, que, por sua vez, norteiam diferentemente as práticas culturais dos grupos. Além disso, a distribuição dos tipos de capital no interior destas classes, isto é, entre as frações de classes, e suas trajetórias e origens sociais (ascensão ou declínio na hierarquia) também são responsáveis por diferentes posições na classe dominante - como, por exemplo, os dominantes dominados - e na classe dominada - como os dominados dominantes, o que também sugere a existência de habitus específicos destas frações de classe (BOURDIEU, 2007).

Neste sentido, o dito "prazer puro", aquele oriundo da apreciação puramente estética, que evita a contemplação de uma obra de arte no sentido de procurar uma função para ela, ou seja, a estética pela estética, desinteressada, a priorização da forma em detrimento da substância, a denegação do "prazer fácil", do prazer gerado pela simples percepção, pelos sentidos e não pela abstração, e, principalmente, a atribuição de valores simbólicos e de maneiras mais "refinadas" a ações cotidianas, desde as mais primárias até as mais complexas, são marcas da influência do habitus das classes mais abastadas nas suas ações. Ao contrário, a negação dos excessivos 
simbolismos, a priorização da substância em detrimento da forma, a busca de uma leitura mais funcional das ações cotidianas, a aceitação do prazer dos sentidos, do prazer direto e a tentativa de se evitar as "firulas" das classes altas são características próprias das classes populares, todas geradas por seu habitus.

Assim, as diferentes formas de se alimentar (regras de etiqueta), de se posicionar o corpo (postura), de se apreciar obras de arte (a arte legítima e consagrada), a prática de diferentes esportes (populares e de elite) e até mesmo as diferentes formas de relação com o próprio corpo sinalizam distintas "filosofias" e formas de se enxergar o mundo social. Na realidade, as classes altas quase sempre procuram, consciente ou inconscientemente, negar a natureza animalesca, o instinto de ser humano, através de seus simbolismos e de seu "refinamento", o que faz com que se distanciem daqueles que não são "finos", isto é, as classes populares. Formas de distinção que procuram atribuir estes estilos de vida a diferentes naturezas, biologicamente falando, mas que, na realidade, são oriundas das diferentes posições ocupadas dentro do espaço social (BOURDIEU, 2007).

Estes estilos de vida se refletem também nos olhares dos turistas. É em decorrência deste fato que o olhar romântico está mais presente nas classes altas, com a valorização simbólica de monumentos naturais e obras de arte, enquanto o olhar coletivo é característico das classes populares, que preferem a fruição nos lugares visitados, a diversão pela diversão, sem a presença marcante do caráter contemplativo encontrado na prática dos primeiros.

A associação do olhar romântico com as classes privilegiadas tem sua origem no sentido que se dava às primeiras aventuras dos viajantes europeus nos séculos XVII e XVIII, estendendo-se até meados do século XIX, quando o turismo começa a tomar os primeiros contornos de fenômeno de massa. Estas primeiras viagens são representadas pelos grand tours, nos quais as expedições preliminares de caráter científico ganham uma versão de sofisticação e refinamento nos segmentos abastados (COUTO, 2007). 
A prática das classes altas de contemplação da natureza, assim como das obras de arte moderna, é acompanhada pela solidão na viagem, uma experiência não compartilhada por grandes grupos. O jovem aristocrata inglês do grand tour partia em uma viagem que durava de seis meses a dois anos, acompanhado apenas por um preceptor e por obras de referência (BOYER, 2003).

A mesma "solidão" também pode ser verificada nos diversos relatos de viajantes da época, como Stendhal e Goethe. Baseado em alguns destes relatos, Nery (1998) realiza uma contraposição da ideologia individualista, presente nas representações eruditas do prazer de viajar, às representações populares de "passeio" alinhadas à ideologia holista. Neste sentido, a ideologia individualista indica uma suposta autonomia individual na utilização da imaginação e na busca por prazer, onde o sujeito é o indivíduo e não o grupo. No caso da ideologia holista, o prazer é idealizado não de forma autônoma, mas sim em relação ao grupo em que o indivíduo se encontra. Dessa maneira, conforma-se uma identificação de práticas no contexto de viagens com diferentes grupos sociais. As classes populares e sua ideologia holista estariam ligadas a "busca do prazer reiterativo" nos deslocamentos "físico-morais" representados pelas viagens de lazer, onde ocorre a mobilização de "padrões pré-dados no estoque do grupo social a que se refere, cuja principal característica situa-se na capacidade que a experiência de um evento ou objeto oferece de ser um lócus da representação naquele padrão" (NERY, 1998, p. 59). Já as "classes médias altas e as elites cultas", baseadas na ideologia individualista, são identificadas pela:

busca do prazer autônomo", mobilizam o prazer enquanto "uma qualidade abstrata da Pessoa, sendo sua característica principal a capacidade supostamente auto-determinada de extrair de qualquer experiência um determinado tipo de lazer (NERY, 1998, p. 59).

Nery (1998) enfatiza ainda mais estas diferenças, contrapondo aspectos dos dois modelos de "formação de pessoa" nos grupos sociais. Caracteriza como "pólo $\mathrm{A}$ " o das classes trabalhadoras e médias baixas, "identificado como 
MELO, Erik Silva Omena de. Aprofundando o olhar do turista: considerações acerca de suas determinantes sociais. Revista Brasileira de Pesquisa em Turismo. v. 3, n. 2, p. 71-94, ago 2009.

ISSN: 1982-6125

'hierárquico/não individualista', 'relacional', 'complementar', 'restrito', 'fechado', 'estereotípico' e 'relation-oriented"'. Da mesma forma, caracteriza o "pólo B", o das classes médias altas e altas, como sendo "'individualista/qualitativo', 'interiorizado', 'autonomizado', 'ampliado', 'aberto', 'reflexivo' e 'person-oriented"'. As características destes grupos sociais estão amplamente presentes, tanto nas práticas dos "passeios" populares, quanto nas das "viagens". Ficam evidentes as semelhanças das categorias olhar coletivo/olhar romântico de Urry (2001) com as categorias prazer reiterativo (ideologia holista)/prazer autônomo (ideologia individualista) de Nery (1998) e suas respectivas conexões com o contexto dos grupos sociais. Estas conexões são explicitadas por Walter (1982 apud URRY, 2001, p.72) no seguinte trecho:

[...] os formadores profissionais de opinião (redatores de folhetos, professores, funcionários das comissões oficiais de turismo, etc.) pertencem em sua maioria à classe média e é no interior dessa classe que se fundamenta, em grande parte, o desejo romântico pelos bens posicionais ${ }^{2}$. Em contraste, o fato de a classe trabalhadora, em sua grande maioria, apreciar a convivência, a sociabilidade e o fazer parte de uma multidão é encarado frequentemente com desprezo por aqueles preocupados em conservar o meio ambiente. É uma pena, pois [...] exalta uma atividade disponível unicamente para os privilegiados.

Apesar dessa polarização entre classes eruditas e classes populares estar presente tanto em Urry (2001) quanto em Nery (1998), ambos os autores fazem ressalvas quanto à rigidez desta classificação. Bourdieu (2007) parece associar o olhar romântico muito mais às frações dominadas da classe dominante, isto é, aos intelectuais do que à burguesia, pois enquanto o burguês prefere "a natureza controlada, balizada, cultivada", os intelectuais

\footnotetext{
${ }^{2}$ Ao contrário dos bens materiais comuns, os bens posicionais não podem ter sua produção incrementada, o que resulta num consumo de soma zero, ou seja, se alguém passa a consumir mais, outras pessoas passarão a consumir menos. Isto significa dizer que esse consumo é essencialmente relacional. "A satisfação que um indivíduo obtém não é infinitamente expansível, mas depende da posição do consumo de uma pessoa em relação ao consumo de outras pessoas". O desejo romântico por esses bens nada mais é do que a necessidade criada de se "consumir" uma paisagem ou lugar de maneira isolada, sem a presença de outras pessoas, consumi-los com exclusividade (URRY, 2001, p.67).
} 
ISSN: $1982-6125$

possuem um "gosto pela natureza propriamente dita, selvagem" (BOURDIEU, 2007). Já Nery (1998, p. 62) afirma que as práticas podem não ser tão "puras" quanto sua classificação sugere:

[...] os modelos A e B não são absolutamente lineares em sua oposição, no sentido de que os portadores da ideologia individualista mantêm subordinado um padrão equivalente ao do "passeio" do modelo holista: seus "fins-de-semana" ou "verões"(em Búzios, Angra ou Petrópolis para as elites e as classes médias do Rio de Janeiro e Campos do Jordão, Ubatuba e Águas de Lindóia para as classes médias paulistas) são tão "reiterativos" quanto as idas à "prainha"3. Apenas eles convivem com as "viagens" de "abertura" que inexistem no outro modelo.

\section{A busca por status}

Segundo Bourdieu (2007), a busca por status é caracterizada pela disputa por capital simbólico e pelo reconhecimento inter e intra classes destas aquisições. Na verdade este capital simbólico faz referência e reverência aos grupos dominantes na sociedade, ou seja, é a alusão às classes mais abastadas, via símbolos diversos, que conferem status ao detentor destes, o que demonstra ou seu pertencimento ao grupo dominante, ou sua vontade de pertencimento ao mesmo. Portanto, é visando às melhores posições dentro da sociedade que ocorre a luta entre grupos, condicionada pelas diferentes relações com a dita cultura legítima, isto é, com a cultura reconhecida pela sociedade como a certa ou verdadeira. Dessa maneira, as formas de distinção entre classes estão baseadas nas expressões de familiaridade com os costumes e práticas da classe dominante. Isto se reflete no acúmulo de capital econômico e cultural de que cada classe dispõe, o que se conforma na existência de uma espécie de mercado destes diferentes capitais que, por sua vez, possuem suas respectivas maneiras e regras de aquisição dentro do

\footnotetext{
${ }^{3}$ Local utilizado como objeto de estudo do autor, situado no município de Nova Ponte/MG, o qual consistia numa praia de represa utilizada por grupos populares como destino de seus "passeios" e de práticas recreativas.
} 
campo social. No que concerne ao capital cultural, as formas de aquisição podem se dar por dois caminhos: pelas instituições escolares, as quais instruem seus freqüentadores quanto à cultura legítima; e pela origem social, isto é, pela classe de nascimento, o que implica, no caso das classes abastadas, na aquisição desta cultura desde cedo pela via familiar antes mesmo de freqüentar as instituições de educação. A obtenção de capital econômico e as possibilidades de ascensão social estarão condicionadas à aquisição de capital cultural, especialmente no que se refere aos grupos dominados. Assim, as distinções almejadas pela classe dominante em relação à classe dominada se dão "naturalmente" por meio da maior familiaridade destes com a cultura legítima. Ainda que dois grupos adotem a mesma prática e/ou costume, esta será realizada de maneira sempre diferente, o que causa a distinção entre estes grupos e irá se refletir, por exemplo, nas formas de se vestir, de falar, de se expressar, de praticar esportes e de viajar.

A atividade turística, considerada do ponto de vista cultural como um costume inerente à determinada sociedade, foi criada por fragmentos das classes dominantes, sendo gradativamente absorvida pelas classes dominadas ao longo dos últimos séculos até tomar a forma de fenômeno de "massa" ou de "indústria", conforme vários autores a denominaram. Esta difusão se deu "de cima para baixo", obedecendo à hierarquia da pirâmide social.

Conforme visto anteriormente, o costume de viajar por prazer tem sua origem nas práticas aristocráticas européias dos séculos XVII, XVIII e XIX. À medida que os costumes aristocráticos obtiveram maior visibilidade, isto é, conhecimento por parte das demais classes sociais outros estratos se sentiram atraídos a tentar seguir estes costumes para se conectar simbolicamente com as classes abastadas, ainda que dentro de suas possibilidades, buscando reconhecimento social (BOYER, 2003; CAMARGO, 2007). É a circulação de informações, proporcionada principalmente por publicações e pela imprensa, que permitirá o aguçamento dos movimentos de invenção, distinção e imitação, caracterizados pelo surgimento de novos hábitos e práticas no seio 
das elites, fazendo com que estas se diferenciem dos demais estratos, para em seguida serem imitadas e, logo após, reinventarem novas formas de distinção. Os primeiros relatos de viagem datam do século XVI, proliferando-se posteriormente, inclusive os de autoria de escritores consagrados nos séculos seguintes como Goethe, Rousseau e Stendhal. Estas publicações - de acesso restrito, devido aos seus custos - em parceria com os guias de viagem eram os responsáveis pela construção do olhar do viajante da época, mecanismo este que viria a ser sistemática e racionalmente elaborado e explorado pela publicidade no século XX.

Conforme estes veículos de informação se massificam, um sistema cultural unificado se solidifica, permitindo a criação de um conjunto único de símbolos, compartilhado pelos diferentes grupos, e a conseqüente difusão dos comportamentos dominantes.

Os nobres possuíam o privilégio de não trabalhar, de poder desfrutar do ócio, de se dar ao luxo de nada fazer por conta de seus direitos adquiridos hereditariamente. Este fato, por si só, já era um grande símbolo de distinção. Da mesma maneira é entendida a viagem como forma de recreação. Viajar sem obrigação, nos séculos XVII e XVIII, significava superioridade. Assim podem ser compreendidos os grand tours, que tiveram como precursora a nobreza inglesa. Já no século XIX, quando a burguesia passa a também viajar por prazer - o que, no século XX, estará ao alcance de outros grupos - a distinção passa a não residir mais simplesmente em viajar, mas sim em para onde e com quem fazê-lo. Neste sentido, será construída a reputação dos diferentes destinos turísticos, algumas se perpetuando até a atualidade, como é o caso, por exemplo, de algumas cidades do litoral mediterrâneo francês, com suas imagens relacionadas à alta sociedade. Outros destinos, no entanto, foram apenas inaugurados pelas elites, criando posteriormente grande atração e fluxo das classes populares. Da mesma maneira, fenômenos que possuem estreita ligação com o turismo atual, são também identificados como inseridos dentro desta lógica de invenção, distinção e imitação. Práticas hoje intituladas 
de populares, como o veraneio, os banhos de mar e a valorização das montanhas também possuem a mesma origem aristocrática (BOYER, 2003).

Além do surgimento desta nova concepção, a transformação das viagens de lazer em formas de consumo alinhadas com os mecanismos de distinção merece maior atenção. O turismo na sociedade ocidental moderna é um meio de consumo: consumo de espaço, de imagens e de sensações. Neste sentido, é importante tentar compreender qual o papel do consumo nesta sociedade.

Ao tratar da sociedade de consumo e do sistema de objetos pertencente a esta, Baudrillard (1993) afirma que os objetos nunca são consumidos em si, isto é, pelo seu valor de uso, mas sim como signos que se inter-relacionam, formando um sistema complexo de significação e comunicação. Nesse sentido, a teoria do consumo baseada na simples satisfação de necessidades básicas e materiais não se aplicaria.

A coerência do sistema funcional dos objetos advém do fato de que estes (em seus diversos aspectos, cor, forma, etc.) não mais têm valor próprio mas (sic) uma função universal de signos. A ordem de natureza (função primária, impulso, relação simbólica) nele se encontra presente por toda a parte, mas unicamente como signo... (BAUDRILLARD, 1993, p. 70)

Assim, a lógica social do consumo é, na verdade, a lógica da produção e manipulação dos significantes sociais. É nesse contexto que os objetos, no sentido lato, são ordenados e sempre manipulados "como signos que distinguem 0 indivíduo, quer filiando-o no próprio grupo tomado como referência ideal quer demarcando-o do respectivo grupo por referência a um grupo de estatuto superior" (BAUDRILLARD, 1991, p.60). Assim, o consumo deve ser visto como forma de distinção social, na qual os indivíduos procuram afirmar suas identidades. No entanto, a busca por status e por prestígio via consumo se manifesta na tentativa de manipulação destes significantes sociais, isto é, os objetos, de maneira que o sujeito da ação "consumir" procure uma espécie de ascensão social simbólica, utilizando-se de um objeto-signo que estaria ligado a um estrato mais elevado do que aquele a que ele pertence. 
É nesta perspectiva que se entende a inserção do consumo turístico. Este está carregado de simbolismos, onde os consumidores procuram se distinguir socialmente, situando os objetos turísticos de consumo dentro de uma rede de significados e significantes. Neste sentido, não viajar seria o mesmo que não possuir um belo carro ou uma bela casa. "É algo que confere status, nas sociedades modernas" (URRY, 2001, p.19).

É importante observar que este processo social de invenção-distinçãoimitação, que se retroalimenta, só existe em grande parte da sociedade por conta da criação desta circulação psicológica de informações sobre os hábitos e costumes de distinção das elites. Com o desenvolvimento dos meios de comunicação e das técnicas publicitárias, especialmente durante o século $X X$, este mecanismo ganha dimensão, acelerando o ciclo, fazendo com que a invenção de modelos (distinção) e a difusão em série (imitação), agora já no contexto industrial, ganhem volume. Com a disseminação da marca de distinção "viajar" nos diferentes estratos sociais, ganha cada vez mais importância o status simbólico que o lugar visitado oferece ao visitante e cada vez menos o simples fato de viajar, em decorrência, principalmente, das conquistas do direito às férias remuneradas por parte da classe trabalhadora no início do século XX. Consequentemente, na segunda metade do século passado o número de destinos turísticos se multiplica numa velocidade cada vez maior. Contribui para isso o fato da circulação de pessoas ter se tornado progressivamente mais ágil, a qual, aliada à circulação de informações já mencionada, torna o ciclo dos destinos turísticos bastante volátil, por conta da maior facilidade de criação e destruição de imagens.

Portanto, as variadas imagens criadas e introjetadas pelos atores sociais destes lugares conferem um status maior ou menor aos seus visitantes. É importante esclarecer que este status, no contexto de grupos internos às classes, é construído e referenciado a partir dos valores internos destes e de sua relação com os demais. Assim, este deslocamento até determinado local envolve o consumo do signo correspondente a ele, o que conferirá ganhos de 
capital social ao turista no retorno ao cotidiano. Isto significa que o consumo turístico é também o consumo de imagens e de seus significados. Novos destinos turísticos significam a criação de novos modelos, que passam à difusão em série, ou seja, ao acesso dos diferentes grupos sociais, até a criação de uma nova diferenciação, de um novo modelo. É a apropriação capitalista deste fenômeno, até o início do século XIX autônomo, de invenção, distinção e imitação que transformará a atividade turística em fenômeno de massa global. No entanto, para que esta criação de modelos e sua difusão em série aconteçam, a manipulação do olhar do turista é essencial.

\section{A manipulação do olhar do turista}

Este direcionamento do olhar do turista foi realizado primeiramente pelas publicações de relatos de viagem e pela imprensa escrita, que divulgavam notícias de atividades das altas classes, fazendo com que os demais estratos passassem a tomar conhecimento dos mesmos e a almejar sua prática em busca de status, de capital simbólico. No século XX, é a publicidade que assume 0 papel principal deste direcionamento, trabalhando 0 condicionamento de um público consumidor, de maneira mais claramente intencionada a fomentar o consumo turístico.

É importante entender que a publicidade possui a função de divulgar as características deste ou daquele produto e promover-lhe a venda, mas, sobretudo, a função de transformar em relação pessoal uma relação comercial, oferecendo calor às relações frias. Apesar de a primeira ser usualmente entendida como primordial, é a segunda que se configura como a mais importante na sociedade de consumo. Isto porque além de ser discurso sobre o objeto de consumo, a publicidade é também um objeto. Os objetos que anuncia são vendidos, mas ela também é ofertada a todos, criando subjetividade e funcionando como forma de integração da sociedade. 
Trata-se, de maneira mais específica, da construção de consensos em torno de necessidades universais, de escolhas e hábitos que homogenizam o público para um direcionamento mais apurado da produção. Estas necessidades universais são geradas principalmente pela publicidade, que procura desenvolver desejos, a ausência de algo, para depois ser remediada com os objetos. Neste sentido, "os desejos, os projetos, as exigências, todos os projetos e todas as relações abstratizam-se (e se materializam) em signos e em objetos para serem compradas e consumidas" (BAUDRILLARD, 1991, p.207). Isto não ocorre por conta de um "maquiavelismo de tecnocratas", e sim devido às características intrínsecas do próprio jogo estrutural da sociedade de consumo.

Não por acaso, o chamado marketing turístico possui forte semelhança com o papel desempenhado pela publicidade. Não só pelo fato do turismo e sua promoção estarem inseridos na sociedade de consumo, mas principalmente em decorrência do grande apelo simbólico e de criação de subjetividades dos quais o turismo se utiliza. Muitos profissionais da área afirmam que a indústria do turismo é uma autêntica "vendedora de sonhos", prometendo a seus clientes o "paraíso na Terra" (KRIPENDORF, 1989), o que aproxima ainda mais o marketing turístico, desenvolvido pelos órgãos promotores, desta função subjetiva. Além disso, na criação de necessidades ("precisa-se viajar", "viajar a lazer é essencial") e na difusão do desejo e do hábito de viajar por grande parte da população, fica claro o peso da formação de subjetividades mencionado.

É o amplo acesso à população provocado pelo desenvolvimento dos meios de comunicação, aliado ao surgimento e aprimoramento das técnicas publicitárias que viabiliza o processo de massificação do turismo. A publicidade em torno de determinado destino turístico não está só vendendo-o com suas características materiais e simbólicas, mas essencialmente criando a necessidade, a carência de viajar por puro prazer, de estar onde outras pessoas - tomadas como boas referências ou modelos - estão. Dessa maneira, 
ela encaminha o indivíduo para sua realização via consumo. Isso se combina com o desejo de ascensão social, que também permeia estas práticas.

A coação do prazer possui estreitas ligações com o surgimento destas necessidades, ocorrendo com a disseminação da idéia de que ser feliz e buscar seu prazer e consumo transformam-se em dever do cidadão. Não é concedida ao consumidor a liberdade de buscar solução para suas carências, mas apenas de aliviar essas tensões decorrentes de suas carências, viajando e consumindo. Assim, por exemplo, viajar seria preciso para se "recarregar as baterias", estar mais disposto para retornar ao trabalho, recuperar a saúde física e mental ou para freqüentar lugares que já foram a destinação de notáveis ou, ainda, para exercer o direito-dever de desfrutar de todos os prazeres que uma viagem pode oferecer. A solidificação destes consensos está diretamente ligada às campanhas publicitárias turísticas, desenvolvidas por um corpo de profissionais, responsáveis por "moldar", direcionar e trabalhar este olhar do turista, divulgando seus produtos, isto é, as localidades eleitas como atrativas e fomentando a reafirmação destas necessidades.

O turismo envolve, necessariamente, o devaneio e a expectativa de novas e diferentes experiências, que divergem daquelas normalmente encontradas na vida cotidiana. Tais devaneios não são autônomos, porém. Envolvem o trabalho com propaganda e outros conjuntos de signos, gerados pela mídia, muitos dos quais dizem respeito claramente a processos complexos de emulação social (URRY, 2001, p. 30).

Portanto, a sacralização e ritualização das viagens de férias na sociedade ocidental moderna devem ser compreendidas como fruto desta criação de subjetividades e necessidades universais, as quais correspondem à coação do prazer, à busca por status e à necessidade de viajar e de experimentar o extraordinário para posteriormente retornar ao ordinário, ao cotidiano, otimizando o funcionamento da força de trabalho no âmbito da produção. $\mathrm{Na}$ verdade, a prática turística de cada grupo social será o resultado da relação entre a manipulação do olhar do turista - que se utiliza, entre outros artifícios, 
da criação e solidificação das necessidades de ruptura sistemáticas e cíclicas com o cotidiano e do fomento ao processo, antes autônomo, de distinção e imitação interclasses - e sua forma de vivenciar a atividade turística, condicionada por seu habitus de classe.

Além da criação de subjetividades, a publicidade também tem por objetivo fomentar o consumo de seus produtos, isto é, dos destinos turísticos, ou, mais especificamente, dos espaços privilegiados destes destinos. Para que este estímulo aconteça, veicula-se uma imagem que atraia consumidores para estes territórios. Neste sentido, as imagens destes lugares são (re)criadas, o que envolve "otimização" e estetização destas. Assim, as partes não desejadas destes espaços são obscurecidas, enquanto a exacerbação e construção estéticas de atrações e de paisagens são engendradas (CASTRO, 1999). As representações destes espaços são, portanto, geradas em benefício do direcionamento do consumo espacial, possuindo papel relevante em sua própria construção, uma vez que as representações hegemônicas influenciam as intervenções espaciais (LÉFÈBVRE, 1994), o que possui grande importância na tentativa de compreensão dos espaços turísticos e de suas formações.

\section{Conclusão}

O processo que move a constituição do olhar do turista, ainda no seu cotidiano, quando ele ainda não é efetivamente um turista, e o impulsiona para o âmbito do extracotidiano é compreendido como resultado da combinação destes elementos, isto é, a manipulação do olhar do turista, a busca por status e ascensão social, a forma de se vivenciar a experiência turística e a expectativa de ruptura com o cotidiano. Cada uma destas esferas condiciona as demais e é ao mesmo tempo por elas condicionada. Algumas características deste processo puderam ser apreendidas. Primeiramente verificou-se que a manipulação do olhar do turista desempenha um papel destacado, na medida em que se apropria dos demais elementos para fins de estímulo de fluxos de 
públicos consumidores com fins de acumulação de capital. Entretanto, é importante ressaltar que nem a expectativa de ruptura com o cotidiano e de evasão, nem a busca por status e muito menos as diferenciadas formas de vivência foram criadas por estes mecanismos de tentativa de manipulação do olhar do turista, mas sim trabalhadas e exploradas pelos mesmos. Se por um lado o fenômeno de invenção - distinção - imitação, antes autônomo, foi intensificado, passando a servir interesses capitalistas, a necessidade de evasão, a princípio criada pelo ambiente urbano cada vez mais hostil e por suas coerções sociais, também seguiu o mesmo caminho. No que concerne às características específicas dos grupos e classes sociais ligados a seus respectivos habitus, a abordagem destes mecanismos toma a forma de nichos e segmentação de mercado, onde estas peculiaridades são trabalhadas para um direcionamento mais preciso do consumo. No entanto, esta última interação é mais presente em países com condições sociais melhores, onde o acesso a viagens de lazer foi mais disseminado entre as diferentes classes.

Além disso, constata-se que a relação entre a busca por status e ascensão social e a forma de se vivenciar a experiência turística é complexa e contraditória. Enquanto a primeira demonstra uma tendência à convergência de práticas turísticas, uma vez que as demais classes são levadas a seguir os hábitos e modelos das classes dominantes através do mecanismo de invenção - distinção - imitação, a segunda, condicionada pelos habitus de classe, leva a uma contratendência no mesmo movimento, pois estes habitus fazem com que, por mais que grupos diferentes realizem atividades muito similares ou até mesmo idênticas, estas serão distintas por conta da maneira como são executadas e vividas. Este fato pode se refletir na presença de diferentes grupos sociais no mesmo destino turístico, muitas vezes até no mesmo ambiente, mas, simultaneamente, numa "natural" distinção em função dos diferentes simbolismos existentes para cada um destes grupos e dos múltiplos comportamentos decorrentes desta variedade. A consideração desta tensão entre estas duas esferas pode ser uma chave para a compreensão de variados 
MELO, Erik Silva Omena de. Aprofundando o olhar do turista: considerações acerca de suas determinantes sociais. Revista Brasileira de Pesquisa em Turismo. v. 3, n. 2, p. 71-94, ago 2009.

ISSN: $1982-6125$

fenômenos, como por exemplo, as territorializações e segregações em espaços turísticos.

\section{REFERÊNCIAS}

BAUDRILLARD, Jean. A sociedade de consumo. Lisboa: Ed. 70, 1991. Sistema dos objetos. São Paulo Perspectiva, 1993.

BAUMAN, Zygmunt. Globalização: as conseqüências humanas. Rio de Janeiro: Jorge Zahar Ed., 1999.

BOURDIEU, Pièrre. Distinção. São Paulo: Edusp, 2007.

BOYER, Marc. História do Turismo de Massa. Bauru, São Paulo: Edusc, 2003.

CAMARGO, Haroldo Leitão. Uma pré-história do turismo no Brasil: recreações aristocráticas e lazeres burgueses (1808-1850). São Paulo: Aleph, 2007.

CASTRO, Celso. Narrativas e imagens do turismo no Rio de Janeiro. In: VELHO, Gilberto. (Org.). Antropologia urbana. Cultura e sociedade no Brasil e em Portugal. Rio de Janeiro, Jorge Zahar, 1999. p. 80-87.

COUTO, Patrícia de Araújo B. Da viagem ao fenômeno turístico: uma breve digressão sobre sua história e inserção no campo das Ciências Sociais. Candelária - Revista do Instituto de Humanidades. jul-dez. 2007.

CRUZ, Rita de Cássia. Política de turismo e território. 3 ed. São Paulo: Contexto, 2002.

FERNÁNDEZ FUSTER, Luis. Teoria y tecnica del turismo. Madrid: Nacional, 1971.

KRIPENDORF, Jost. Sociologia do Turismo. Rio de Janeiro: Civilização Brasileira, 1989.

LÉFÈBVRE, Henri. The production of space. Oxford: Blackwell, 1994.

NERY, Paulo Roberto Albieri. Viagem, passeio, turismo: estudo comparado do deslocamento como valor. 1998. Tese (Doutorado em Antropologia), Universidade Federal do Rio de Janeiro/Museu Nacional/PPGAS, Rio de Janeiro: 1998.

PANOSSO NETTO, Alexandre. Filosofia do Turismo: teoria e epistemologia. São Paulo: Aleph, 2005.

TRIBE, John. The (in) discipline of tourism. Annals of Tourism Research, v. 24, n. 3, p. 38-657, 1997. 
MELO, Erik Silva Omena de. Aprofundando o olhar do turista: considerações acerca de suas determinantes sociais. Revista Brasileira de Pesquisa em Turismo. v. 3, n. 2, p. 71-94, ago 2009.

ISSN: 1982-6125

URRY, John. O olhar do turista: lazer e viagens nas sociedades contemporâneas. São Paulo: Studio Nobel/SESC, 2001.

Recebido em março de 2009.

Aprovado em junho de 2009. 